\title{
Antarctic ice sheet thickness estimation using the horizontal-to-vertical spectral ratio method with single-station seismic ambient noise
}

\author{
Peng Yan ${ }^{1}$, Zhiwei $\mathrm{Li}^{2}$, Fei $\mathrm{Li}^{1,3}$, Yuande Yang ${ }^{1}$, Weifeng $\mathrm{Hao}^{1}$, and Feng Bao ${ }^{2}$ \\ ${ }^{1}$ Chinese Antarctic Center of Surveying and Mapping, Wuhan University, Wuhan 430079, China \\ ${ }^{2}$ State Key Laboratory of Geodesy and Earth's Dynamics, Institute of Geodesy and Geophysics, \\ Chinese Academy of Sciences, Wuhan 430077, China \\ ${ }^{3}$ State Key Laboratory of Information Engineering in Surveying, Mapping and Remote Sensing, \\ Wuhan University, Wuhan 430079, China
}

Correspondence: Fei Li (fli@whu.edu.cn)

Received: 9 August 2017 - Discussion started: 11 September 2017

Revised: 12 January 2018 - Accepted: 18 January 2018 - Published: 2 March 2018

\begin{abstract}
We report on a successful application of the horizontal-to-vertical spectral ratio $(\mathrm{H} / \mathrm{V})$ method, generally used to investigate the subsurface velocity structures of the shallow crust, to estimate the Antarctic ice sheet thickness for the first time. Using three-component, five-day long, seismic ambient noise records gathered from more than 60 temporary seismic stations located on the Antarctic ice sheet, the ice thickness measured at each station has comparable accuracy to the Bedmap2 database. Preliminary analysis revealed that 60 out of 65 seismic stations on the ice sheet obtained clear peak frequencies (f0) related to the ice sheet thickness in the $\mathrm{H} / \mathrm{V}$ spectrum. Thus, assuming that the isotropic ice layer lies atop a high velocity half-space bedrock, the ice sheet thickness can be calculated by a simple approximation formula. About half of the calculated ice sheet thicknesses were consistent with the Bedmap2 ice thickness values. To further improve the reliability of ice thickness measurements, two-type models were built to fit the observed $\mathrm{H} / \mathrm{V}$ spectrum through non-linear inversion. The two-type models represent the isotropic structures of single- and twolayer ice sheets, and the latter depicts the non-uniform, layered characteristics of the ice sheet widely distributed in Antarctica. The inversion results suggest that the ice thicknesses derived from the two-layer ice models were in good concurrence with the Bedmap2 ice thickness database, and that ice thickness differences between the two were within $300 \mathrm{~m}$ at almost all stations. Our results support previous finding that the Antarctic ice sheet is stratified. Extensive
\end{abstract}

data processing indicates that the time length of seismic ambient noise records can be shortened to two hours for reliable ice sheet thickness estimation using the $\mathrm{H} / \mathrm{V}$ method. This study extends the application fields of the $\mathrm{H} / \mathrm{V}$ method and provides an effective and independent way to measure ice sheet thickness in Antarctica.

\section{Introduction}

The Antarctic ice sheet is the largest on the Earth, covering over $98 \%$ of Antarctic continent. As a fundamental parameter of the Antarctic ice sheet, ice sheet thickness is significant for dynamic ice sheet modeling of mass balance and sea level changes (Budd et al., 1991; Gogineni et al., 2001; Bamber et al., 2001; Hanna et al., 2013). Seismic waves also become more complex when traveling through an ice sheet with thicknesses ranging from hundreds to thousands of meters. Thus, accurate ice sheet thickness is a critical metric for recognizing and denoising seismic multiples trapped inside the ice sheet when imaging crustal and mantle structures below the ice sheet (Lawrence et al., 2006; Hansen et al., 2009, 2010). Therefore, a better understanding of ice sheet thickness and structures can also improve the study of the geological structure underneath the ice sheet in Antarctica.

Given the importance of Antarctic ice sheet structures, many geophysical methods, such as drilling, gravity modeling, radio echo sounding (RES) and active seismic ap- 
proaches including reflection and refraction, have been used in local- or regional-scale ice sheet thickness investigations since the 1950s (Bentley and Ostenso, 1961; Bentley, 1964; Evans and Robin, 1966; Evans and Smith, 1969; Robin, 1972; Drewry et al., 1982; Cui et al., 2016). By studying gravitational anomalies in the ice sheet, one utilizes gravimetric measurements to provide an indirect way to infer the average ice thickness over a region. Active seismic and RES methods can determine the ice thickness over a much smaller area by converting the echo time of seismic and electromagnetic waves into an estimation of ice thickness. Among these methods, the active seismic and RES methods are the most widely used techniques for ice thickness measurements due to their relatively high accuracy and better spatial resolution, while gravity modeling is used as a complementary way in areas where direct ice thickness measurements are lacking. Using these methods (with the dominance of the RES method), abundant ice thickness data has been collected over the past few decades. Compiled and gridded, these increasing data volumes were used to construct the Bedmap1 and Bedmap2 databases at a resolution of 5 and $1 \mathrm{~km}$, respectively (Lythe et al., 2001; Fretwell et al., 2013). However, traditional methods for estimating ice thickness still have limitations. For example, the accuracy of the gravity method is relatively low because of the intrinsically low sensitivity of a gravimeter to the gravitational anomalies related to the ice-sheet-bedrock interface. In the case of the active seismic and RES methods, considerable economic and logistical support is required to collect the data. With the rapid growth of cryo-seismology in the last one to two decades, many passive seismic methods have been applied to cryospheric research (Podolskiy and Walter, 2016; Aster and Winberry, 2017). Given that passive seismic methods can mitigate logistical problem and are relatively cost-efficient (Zhan et al., 2014; Picotti et al., 2017), it is therefore of interest to explore the feasibility of passive seismic methods to contribute additional and/or better constraints to the ice sheet structure.

Teleseismic P-wave receiver functions (PRFs), as a generally used passive seismic method to determine crustal and mantle discontinuities, is also sensitive to the ice-bedrock interface and the seismic properties of ice sheets. Hansen et al. (2010) successfully modeled ice sheet thickness beneath several stations in East Antarctica using PRFs. Wittlinger and Farra $(2012,2015)$ investigated the anisotropy of the polar ice sheet by modeling the P-to-S wave conversion with the negative PRF amplitude. Yan et al. (2017) confirmed that the ice thickness results derived from PRFs are consistent with the Bedmap2 ice thickness database. However, large numbers of teleseismic events are needed to perform PRFs; it usually requires at least a one-year data collection period, thus greatly limiting the application of the PRF method in harsh environments such as those found in Antarctica.

In order to improve the efficiency of ice thickness investigation, we selected the horizontal-to-vertical spectral ratio $(\mathrm{H} / \mathrm{V})$ method to determine ice thickness. As a passive and non-invasive seismic method, the $\mathrm{H} / \mathrm{V}$ technique has been extensively used in seismic exploration as a tool to detect sediment thickness (Konno and Ohmachi, 1998; Ibs-von Seht and Wohlenberg, 1999; Bonnefoy-Claudet et al., 2006). Considering that the sediments and ice sheet layer are both low shear-wave velocity $\left(V_{\mathrm{s}}\right)$ layers atop the high velocity bedrock, the $\mathrm{H} / \mathrm{V}$ method should be suitable for determining ice sheet thickness.

Lévêque et al. (2010) applied the H / V method to four stations in the Dome $\mathrm{C}$ region of Antarctica for inferring the uppermost snow layer thickness and its corresponding ice properties to a few meters depth. Picotti et al. (2017) recently adopted the $\mathrm{H} / \mathrm{V}$ method to detect glacial ice thickness ranging from a few tens of meters to $\sim 800 \mathrm{~m}$ in Italy, Switzerland, and West Antarctica. The H / V method has been validated for its reliability to measure glacial thickness, when compared to the radio-echo sounding, geoelectric and active seismic methods implemented at or near the same study sites. The great advantage of the $\mathrm{H} / \mathrm{V}$ method over other approaches is that there is no need to record earthquakes or active sources, since it utilizes seismic ambient noise. Moreover, the $\mathrm{H} / \mathrm{V}$ method only requires a few tens of minutes of seismic ambient noise recordings at single portable threecomponent seismometers. This greatly enhances efficiency and reduces cost and logistical support requirements.

Shear-wave velocity is an important parameter that controls the shear-wave impedance contrast (product of density and shear-wave velocity) at the interface between the upper and the lower layers. Since the shear-wave velocity of an ice sheet is $\sim 1900 \mathrm{~m} \mathrm{~s}^{-1}$, and generally much higher than a snow layer $\left(\sim 700 \mathrm{~m} \mathrm{~s}^{-1}\right)$, the impedance contrast of the ice-sheet-bedrock half-space is not as high as that of the snow-ice sheet layer. Moreover, the H / V spectrum may be more complicated than that of a glacier or snow layer, given the complex subglacial environment and possible existence of subglacial lakes and sedimentary layers. In addition, the internal ice structure might affect the $\mathrm{H} / \mathrm{V}$ spectrum given the variations in seismic velocities induced by changes in density and temperature, as well as the ice crystal size and orientation of an ice sheet. Whether the $\mathrm{H} / \mathrm{V}$ method can be used to estimate the ice sheet thickness or not remains an open question. Although the $\mathrm{H} / \mathrm{V}$ method has been successfully applied to study snow and shallow glacial thickness (Lévêque et al., 2010; Picotti et al., 2017), to our knowledge, the $\mathrm{H} / \mathrm{V}$ method has not yet been utilized to estimate Antarctic ice sheet thickness. In this study, we present estimated ice thickness results from 65 stations with a typical coverage deployed on the Antarctic ice sheet to verify the feasibility of using the $\mathrm{H} / \mathrm{V}$ method as an effective way to measure ice thickness. 


\section{Data and methods}

\subsection{Data}

Over the past two decades, several temporary seismic arrays have been deployed in Antarctica, including the TransAntarctic Mountains Seismic Experiment (TAMSEIS, 2000-2003) (Lawrence et al., 2006), the Gamburtsev Antarctic Mountains Seismic Experiment (GAMSEIS, 2007-2012) (Hansen et al., 2010) and the Polar Earth Observing Network/Antarctic Network (POLENET/ANET, 2007-2016) (Chaput et al., 2014). Despite their relatively sparse distribution compared to many dense seismic arrays on other continents, these three arrays combined effectively cover East and West Antarctica as well as the Transantarctic Mountains region (Fig. 1). In these three arrays, all stations are equipped with the Güralp CMG-3T or Nanometrics T-240 broadband sensors with a sampling rate of 25 or $40 \mathrm{~Hz}$. Most stations are buried 1-2 $\mathrm{m}$ below the surface snow to guarantee data quality (mainly to ensure good coupling and to dampen wind noise) (Anthony et al., 2015). Equipped with solar panels and rechargeable batteries, the GAMSEIS and POLENET/ANET stations work continuously year round except the TAMSEIS and provide abundant seismic ambient noise waveforms for the $\mathrm{H} / \mathrm{V}$ processing. To investigate the effectiveness of the $\mathrm{H} / \mathrm{V}$ method for ice thickness measurements and the appropriate length of time for $\mathrm{H} / \mathrm{V}$ processing, we selected seismic ambient noise records lasting about five days (an example of such raw ambient noise record is shown in Supplement Fig. S1), which is much longer than that used in usual H / V data processing (only a few minute long records for sedimentary investigations for tens to hundreds of meters thick). In total, 65 stations deployed on the Antarctic ice sheet were used in this study.

\subsection{Methods}

The single-station H / V method, extensively used in sediment structure detection, acquires reliable sediment thickness and shear-wave velocities (Nogoshi and Igarashi, 1971; Nakamura, 1989). In this method, seismic ambient noise data are collected by a three component seismometer and the ratio between the horizontal $(\mathrm{H})$ and vertical $(\mathrm{V})$ Fourier spectra are calculated. The principle of the technique can be understood by assuming a low velocity sedimentary layer overlying a high velocity bedrock half-space. Due to the sharp impedance contrast at the interface between the two layers, the shear-wave energy within the sedimentary layer produces a prominent peak that can be observed in the $\mathrm{H} / \mathrm{V}$ spectrum.

During the relatively long history of the $\mathrm{H} / \mathrm{V}$ method, extensive field experiments and numerical simulations have been carried out to confirm the correspondence between the shear-wave resonance frequency and the $\mathrm{H} / \mathrm{V}$ peak frequency. Initially Nakamura (1989) proposed that the peak frequency corresponds to the transfer function for vertically

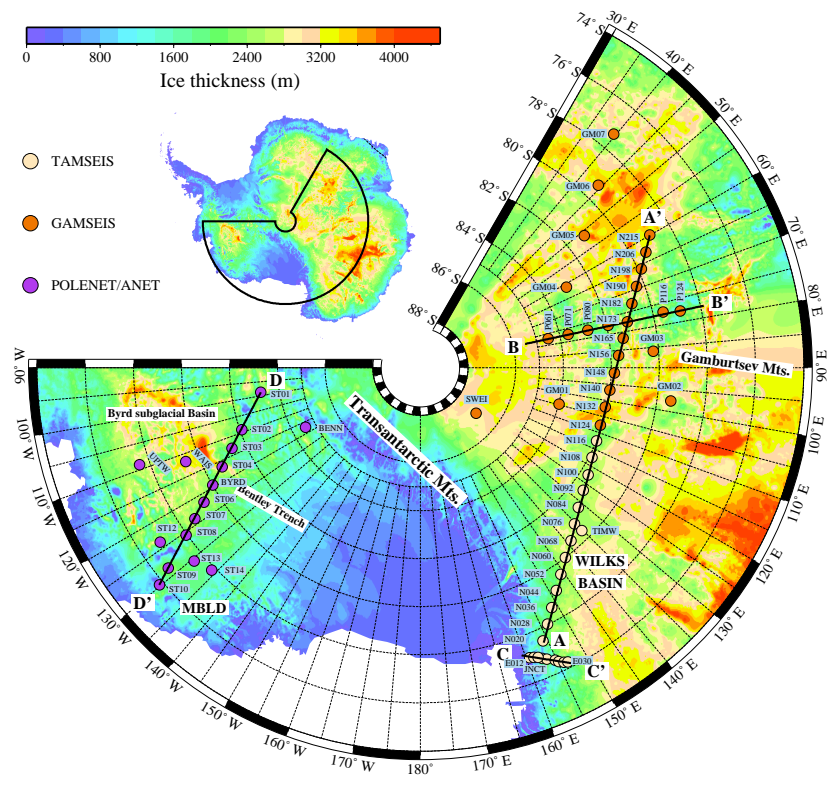

Figure 1. Locations of the three seismic arrays used in this study. Some stations are connected with lines to form four profiles marked with AA', BB', CC' and DD'. TAMSEIS: TransAntarctic Mountains Seismic Experiment; GAMSEIS: Gamburtsev Antarctic Mountains Seismic Experiment; POLENET/ANET: The Polar Earth Observing Network/Antarctic Network. Ice sheet thickness data in this plot come from Bedmap2 database.

incident SH waves (a polarized shear-wave that is generated when an incident shear-wave enters in a heterogeneous medium). Using numerical simulations of ambient noise in a soil layer overlying a hard bedrock, Lachetl and Bard (1994) first showed that the peak frequency is very close to the shear-wave resonance frequency. This correspondence between the $\mathrm{H} / \mathrm{V}$ peak frequency and the shear-wave resonance frequency was later confirmed by Bard (1998), Ibsvon Seht and Wohlenberg (1999), and reasserted by Nakamura (2008). The peak in the H / V spectrum may also be followed by a trough. Konno and Ohmachi (1998) found such feature in the $\mathrm{H} / \mathrm{V}$ spectrum in the case of a soft sediment layer atop a hard bedrock. As pointed out by Tuan et al. (2011), the appearance of a trough probably suggests that the overlying layer has higher Poisson's ratio (or impedance contrast) than that of the underlying layer. Despite this, the $\mathrm{H} / \mathrm{V}$ peak frequency is commonly accepted as a proxy for the resonance frequency of a particular layer. No strong evidence supports that the peak amplitude indicates the amplification factor of the site and there is some controversy about the nature of the ambient noise wave field and its sources (Sánchez-Sesma et al., 2011). During the past few decades, two research branches have formed to interpret the ambient noise wave field: Rayleigh wave ellipticity (Fäh et al., 2001; Wathelet et al., 2004) and the full wave-field assumptions, including distributed surface sources (DSSs, Lunedei and 
Albarello, 2009, 2010) and diffuse field assumption (DFA, Shapiro and Campillo, 2004; Sánchez-Sesma and Campillo, 2006; Sánchez-Sesma et al., 2011; García-Jerez et al., 2013, 2016).

To calculate the H / V spectrum, a specialized GEOPSY program was developed by the European SESAME team, and widely used to investigate sediment structures (Bard and SESAME Team, 2005). An approximation equation or H / V spectrum inversion approach can then be used to derive the sedimentary layer thickness using the $\mathrm{H} / \mathrm{V}$ spectrum.

Under the assumption of one-dimensional velocity subsurface conditions, in cases of homogenous and isotropic sedimentary layers over a homogenous half-space, the observed peak frequency equals the fundamental resonance frequency of the sedimentary layer. Thus, the resonance frequency of the low velocity layer is closely related to its thickness $(h)$ via the following relationship (Ibs-von Seht and Wohlenberg, 1999; Parolai et al., 2002; Picotti et al., 2017; Civico et al., 2017):

$h=\frac{V_{\mathrm{s}}}{4 f_{0}}$,

where $V_{\mathrm{s}}$ is the average shear-wave velocity of the sedimentary layer, and $f_{0}$ is the observed peak frequency. Provided that a correct estimate of the average shear-wave velocity of the sedimentary layer is available, its thickness can be approximately estimated.

Complicated sedimentary internal structures, including anisotropy and low velocity layers beneath stations, will affect the $\mathrm{H} / \mathrm{V}$ spectrum and consequently violate the assumptions of Eq. (1). Therefore, when inferring complex subsurface structures, an inversion of the full $\mathrm{H} / \mathrm{V}$ spectrum can be used to more accurately explain the observed $\mathrm{H} / \mathrm{V}$ spectrum. Based on different assumptions (including Rayleigh wave ellipticity, DSSs, and DFA) for the interpretation of ambient noise wave-field composition, several inversion schemes have been proposed and successfully applied to study sedimentary structures (Fäh et al., 2003; Arai and Tokimatsu, 2004; Herak, 2008; Lunedei and Albarello, 2009; Sánchez-Sesma et al., 2011). These assumptions differentiate themselves in the scheme of forward calculation of the $\mathrm{H} / \mathrm{V}$ spectrum. In this study, a more recently developed $\mathrm{H} / \mathrm{V}$ spectrum forward calculation and inversion method based on the DFA was employed (García-Jerez et al., 2016). The DFA was proposed on the basis of the recently stated connection between the diffuse fields and the Green's function which arises from the ambient noise interferometry theory. Under this assumption, the average spectral power $(P(\omega))$ of a diffuse field along each Cartesian axis is proportional to the imaginary part of Green's tensor components at an arbitrary point $x$ and circular frequency $\omega$ (i.e., $P_{i}(\omega) \propto \operatorname{Im}\left[G_{i i}(x ; x ; \omega)\right], i=1,2,3$, where 1 and 2 stand for the horizontal directions and 3 denotes the vertical direction; terms with 1 and 2, in fact, are equal). Thus, the $\mathrm{H} / \mathrm{V}$ spectral ratio is given as

$\mathrm{HV}(x ; \omega)=\sqrt{\frac{P_{1}(x ; \omega)+P_{2}(x ; \omega)}{P_{3}(x ; \omega)}}=\sqrt{\frac{2 \operatorname{Im}\left[G_{11}(x ; x ; \omega)\right]}{\operatorname{Im}\left[G_{33}(x ; x ; \omega)\right]}}$.

In a horizontally layered structure, the contribution of both the surface wave and the body wave to the $\operatorname{Im}\left[G_{i i}(x ; x ; \omega)\right]$ (on the right-hand side of Eq. 2) can be computed with provided medium properties including primary- and shear-wave velocities. The detailed formulations are not stated here on account of space limitations, but interested readers may refer to Sánchez-Sesma et al. (2011), Lunedei and Malischewsky (2015), and García-Jerez et al. (2016). Thus, Eq. (2) allows for the $\mathrm{H} / \mathrm{V}$ spectrum inversion as it links the real measurements and the theoretical calculation of an $\mathrm{H} / \mathrm{V}$ spectrum. In the $\mathrm{H} / \mathrm{V}$ spectrum inversion procedure, model spaces are set for parameters including primary- and shear-wave velocities, mass density and the thickness of each layer. The sedimentary structures can be determined when the lowest misfit between the observed and forward calculated $\mathrm{H}$ / V spectrum is obtained using inversion algorithms such as Monte Carlo sampling and simulated annealing.

$E(m)=\frac{\sum_{j}\left(\mathrm{HV}^{\mathrm{obs}}-\mathrm{HV}_{j}^{\text {theo }}(m)\right)^{2}}{\sigma^{2}}$,

where $E(m)$ is the lowest value of the misfit in the $j$ iterations, and $m$ represents a model that is comprised of primaryand shear-wave velocities, mass density and the thickness of each layer in each iteration. $\mathrm{HV}^{\mathrm{obs}}, \mathrm{HV}_{j}^{\text {theo }}(m)$ are the observed and the $j$ th forward calculated $\mathrm{H} / \mathrm{V}$ spectrum, respectively, and $\sigma$ is the standard deviation associated with the $\mathrm{HV}^{\mathrm{obs}}$.

The H / V method has been successfully applied in studies of sedimentary structures (Ibs-von Seht and Wohlenberg, 1999; Langston and Horton, 2014; Civico et al., 2017). However, applications in ice environments are rare. Lévêque et al. (2010) studied the snow layer thickness and the ice properties beneath four stations in the Dome $\mathrm{C}$ region of Antarctica using the H / V method. Picotti et al. (2017) measured ice thickness ranging from tens of meters to $800 \mathrm{~m}$ of six glaciers in Italy, Switzerland and West Antarctica. However, the impedance contrast between the ice sheet layer and the overlying bedrock is not as high as that of sedimentarybedrock and snow-ice layers. Moreover, the complex subglacial environment and internal ice structure create other technical obstacles. Thus, there have been no investigations of ice sheet thickness incorporating the $\mathrm{H} / \mathrm{V}$ method for measurements or estimations.

In this study, the $\mathrm{H} / \mathrm{V}$ spectra of 65 stations deployed on ice were processed using the GEOPSY software. Under the general assumption that the seismic properties are stable throughout the whole ice column, we calculated the ice thickness using Eq. (1), as in most seismological applications, to approximate the ice sheet as a homogeneous layer. Mean- 

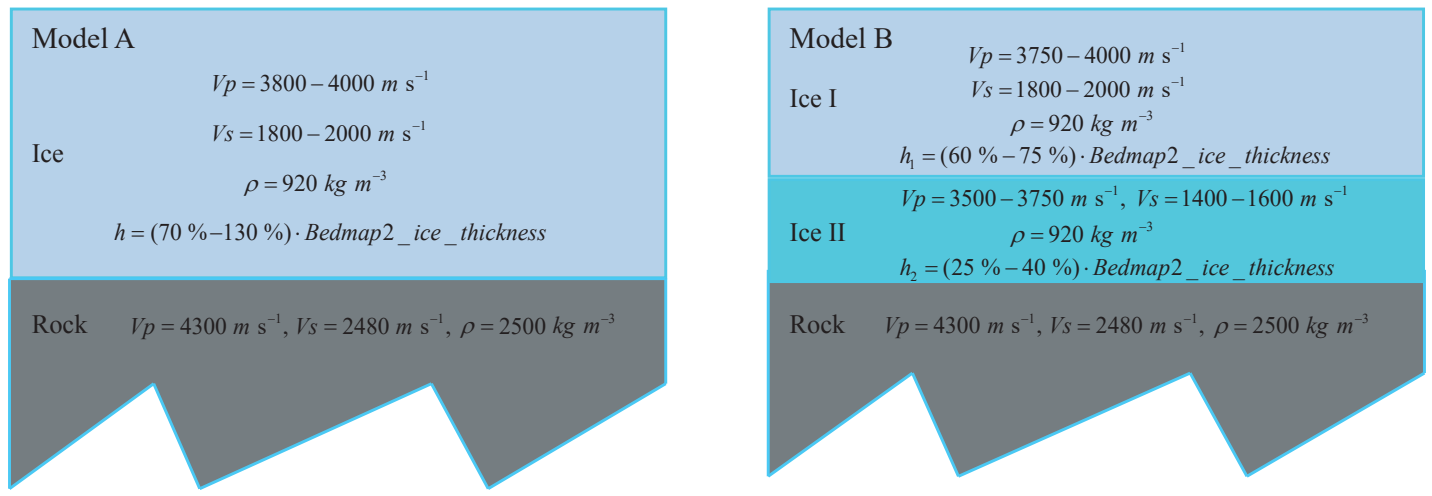

Figure 2. Sketches of the two ice layer models used for H / V spectrum inversion. Model A comprises a single ice layer, while model B is a two-layer ice structure with low shear-wave velocity in the lower ice layer. The parameters used in the two models are consistent with Wittlinger and Farra (2012).

while, a non-linear $\mathrm{H} / \mathrm{V}$ spectrum inversion method developed by García-Jerez et al. (2016) was adopted to constrain the observed $\mathrm{H} / \mathrm{V}$ spectrum to infer the ice structure, comprised of shear-wave velocity and thickness.

During $\mathrm{H} / \mathrm{V}$ spectrum acquisition using the GEOPSY software, we removed the transient signals (earthquakes) from noise records with the STA/LTA technique and divided the records into $600 \mathrm{~s}$ length windows with an overlap of $5 \%$. Time series were tapered with a $5 \%$ cosine function, and the fast Fourier transform was calculated for each component. The spectra were smoothed with a Hanning window in a bandwidth of $0.1-2 \mathrm{~Hz}$ on a logarithmic frequency scale. The spectra of the two horizontal components (N-S and $\mathrm{E}-\mathrm{W})$ were merged to one horizontal component spectrum by calculating their geometric mean. The spectral ratios and corresponding standard deviation estimates between the horizontal component and the vertical component were calculated.

Having acquired the resonance frequency of the ice sheet, we adopted Eq. (1) with a uniform average shear-wave velocity $-1900 \mathrm{~m} \mathrm{~s}^{-1}-$ of the ice layer to calculate the ice thickness. The velocity used here is reasonable given that it is in the general range of ice determined by seismic experiments (Kim et al., 2010). Moreover, this velocity has also been widely used in previous studies (Hansen et al., 2010; Wittlinger and Farra, 2012; Ramirez et al., 2016). Keeping the velocities set, the ice thickness at each station was then calculated using Eq. (1).

In the $\mathrm{H} / \mathrm{V}$ spectrum inversion procedures, Bedmap2 ice thicknesses were used as references to build the initial models, along with the related seismic elastic parameters (Fig. 2, Wittlinger and Farra, 2012; Ramirez et al., 2016). We adopted two different models to perform $\mathrm{H} / \mathrm{V}$ spectrum inversion: the first model assumes that the ice sheet is homogenous, whist the second assumes that the inner ice is stratified (as shown in Fig. 2). Model A is a simple homogeneous and isotropic ice structure with an ice layer overlying the halfspace. In this model, the ice thickness varies from 0.7 to 1.3 times the Bedmap2 ice thickness for each station. Model B is constructed following Wittlinger and Farra $(2012,2015)$ as a two-layer ice structure in which a low shear-wave velocity lies in the lower ice layer. In this model, the thickness of the upper ice layer and the lower ice layer were set to occupy $60-75$ and $25-40 \%$ of the Bedmap2 thickness, respectively. Using the non-linear Monte Carlo method (García-Jerez et al., 2016), we retrieved the optimum solutions for model A and $\mathrm{B}$. These two solutions were best fitted to the observed $\mathrm{H} / \mathrm{V}$ spectrum.

It usually takes a few minutes to about half an hour to collect seismic ambient noise waveforms in investigations of sedimentary layers with thickness ranging from several tens to hundreds of meters. However, there is no prior reference for the time length required for recording seismic ambient noise in the Antarctic ice sheet with several kilometers thick. It is necessary to apply the $\mathrm{H} / \mathrm{V}$ method with a much shorter recording time for seismic ambient noise, considering the harsh environment and logistical support difficulties in Antarctica. Therefore, we investigated the feasibility and reliability of $\mathrm{H} / \mathrm{V}$ method by testing a range of noise record lengths; eight hour, four hour, two hour and one hour intervals were tested. The processing strategies remained the same as in $\mathrm{H} / \mathrm{V}$ spectrum acquisition except the window length was changed to $200 \mathrm{~s}$ when calculating the H / V spectrum using different length noise records.

\section{Results}

In this study, the $\mathrm{H} / \mathrm{V}$ spectra of 65 stations were obtained. Figure 3 displays the $\mathrm{H} / \mathrm{V}$ spectra of nine stations selected from three arrays. These examples are representative of all the results, and the remaining spectra are presented in the Supplement Fig. S2. It is clearly shown that in almost all $\mathrm{H} / \mathrm{V}$ spectra there were two or three clear peaks in the frequency band. Generally, the largest amplitude appears at the first peak located around $0.2 \mathrm{~Hz}$ or below, and the second 


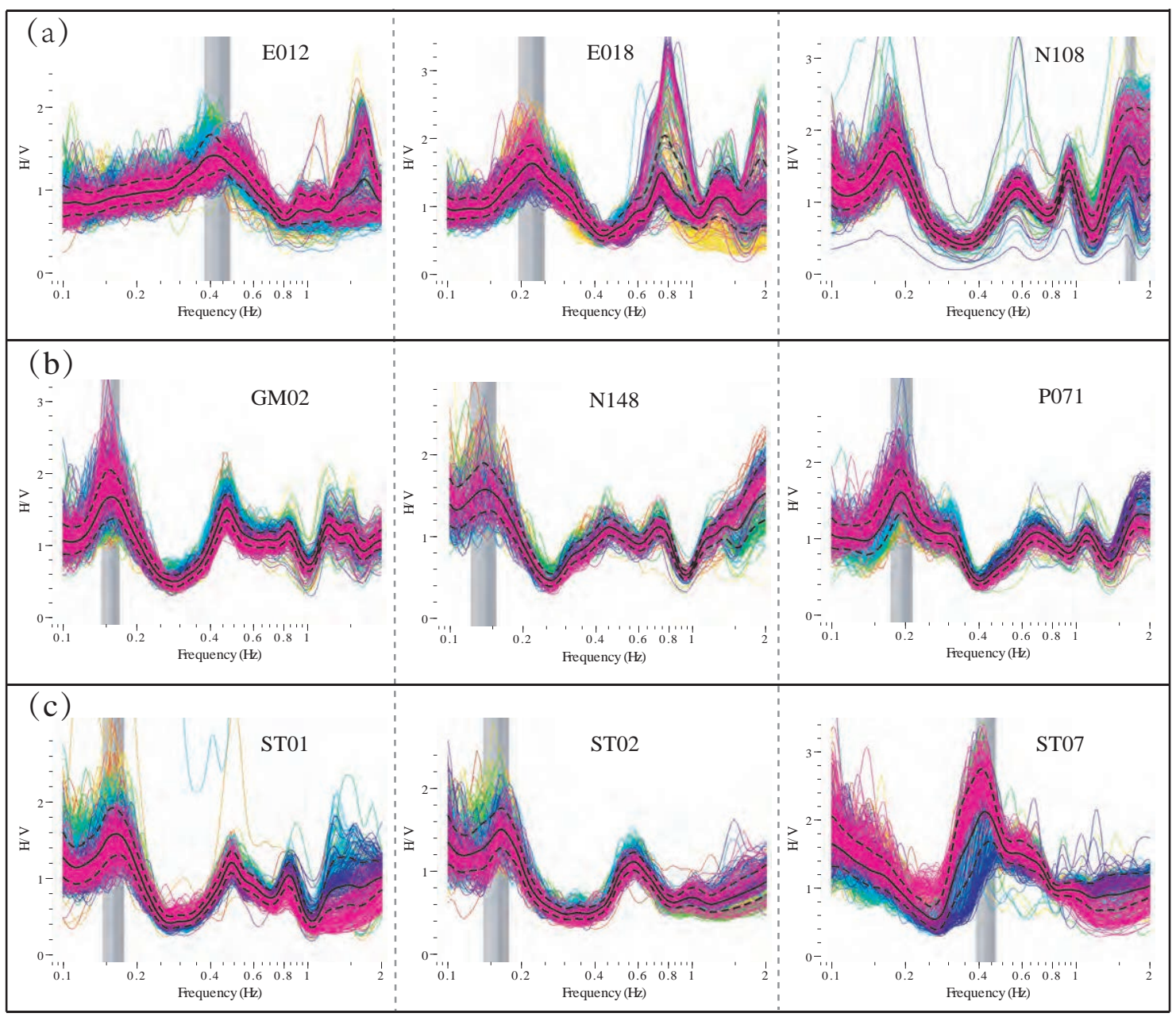

Figure 3. H / V spectra of nine stations shown as representative of all results in this study. Panel (a), (b) and (c) are each comprised of three stations that belong to the TAMSEIS, GAMSEIS and POLENET/ANET arrays, respectively (the locations can be seen in profiles displayed in Fig. 4). The H / V spectra were calculated using five-day long ambient noise records. In each spectrum, the value at the limit between the two vertical grey areas is the peak frequency, while the two grey areas denote its standard deviation. The spectra of the E012, E018, GM01, N148, P071, ST01 and ST02 stations represent 42 stations, where the clear first peaks with the largest amplitudes are in agreement with the resonance frequency of the ice sheet layer. Station N108 is representative of 18 stations, where the first peaks are related to the ice sheet resonance frequency but with slightly lower amplitude than peaks in higher frequencies. ST07 is the example that where no correlation of the peak frequency with the ice thickness appears, as expected in the observed $\mathrm{H} / \mathrm{V}$ spectrum.

and the third peaks with lower amplitudes are located at $\sim 0.5$ and $\sim 0.8 \mathrm{~Hz}$, respectively. Following the general interpretation principles for $\mathrm{H} / \mathrm{V}$ spectra (Bard and SESAME Team, 2005), the peak frequency denoting the largest amplitude should be the resonance frequency of the ice sheet layer, while the peaks appearing with lower amplitudes at higher frequencies may indicate shallower impedance contrast layers. The reasonableness of considering the first peak frequency with the largest amplitude as the resonance frequency of the ice sheet layer was verified through approximate estimation based on Eq. (1), i.e., for station E012, the Bedmap2 ice thickness at that location is $1050 \mathrm{~m}$, so the resonance frequency according to Eq. (1) should be $0.452 \mathrm{~Hz}$ (the given $V_{\mathrm{s}}$ is $1900 \mathrm{~m} \mathrm{~s}^{-1}$ ) and this was observed as expected
$(0.418 \pm 0.052 \mathrm{~Hz})$ in the $\mathrm{H} / \mathrm{V}$ spectrum. However, there are exceptions such as station N108 displayed in Fig. 3, where the first peak $(0.177 \pm 0.014 \mathrm{~Hz})$ amplitude is slightly lower than that of the following peak observed at higher frequency $(1.666 \mathrm{~Hz})$. At this station, however, the location of the first peak correlates with the resonance frequencies $(0.194 \mathrm{~Hz})$ through approximate estimation. In addition, there are some stations that have no peak frequencies correlating with the ice sheet thickness, despite the existence of peak frequency with strong amplitude in the frequency band. Station ST07 seen in Fig. 3 is such a case, where the fundamental resonance frequency as calculated by Eq. (1) should be $0.191 \mathrm{~Hz}$ (its Bedmap2 ice thickness is $2490 \mathrm{~m}$ ). Nevertheless, no clear peak around this expected frequency is observed in the $\mathrm{H} / \mathrm{V}$ 

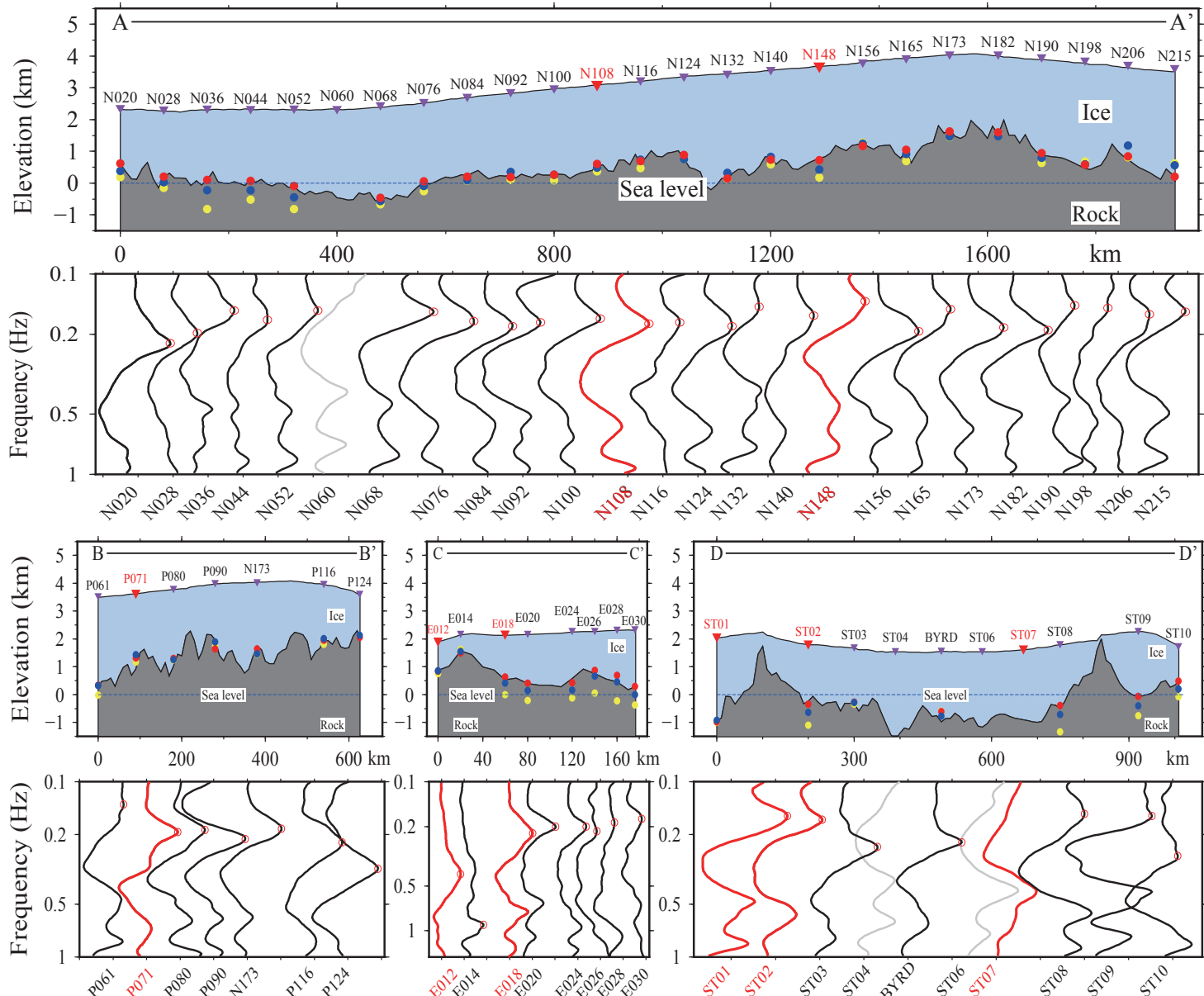

Figure 4. Cross section showing $\mathrm{H} / \mathrm{V}$ spectra and the ice sheet thickness obtained from the $\mathrm{H} / \mathrm{V}$ method at stations along the four profiles (Fig. 1). In the below $\mathrm{H} / \mathrm{V}$ spectra cross section panels, the red circles denote the resonance frequencies correlating to the ice thickness for each station. The spectra of the four stations without clear peaks are plotted with grey lines. The spectra together with their station names that are shown in red, correspond to the stations displayed in Fig. 3. The upper panels show the variation of the bedrock and ice surface elevation along each profile obtained from Bedmap2 database. In these plots, the red dots indicate the reference Bedmap2 ice thickness, while the yellow and the blue dots represent the Eq. (1) estimates and the DFA + Model B estimates, respectively.

spectrum. We therefore can group the results into three categories:

1. 42 stations with first peaks denoting the largest amplitude in the observed spectrum related to the ice sheet resonance frequency (e.g., the E012, E018, GM02, N148, P071, ST01 and ST02 stations in Fig. 3).

2. 18 stations with first peaks with slightly lower amplitude but also related to the ice sheet resonance frequency (such as station N108).

3. Five stations without peaks correlating to the resonance frequency (such as station ST07).

Figure 4 shows the $\mathrm{H} / \mathrm{V}$ spectra of stations along four profiles, together with the ice sheet and bedrock elevation extracted from the Bedmap2 database for each station. As shown in Fig. 4, although the neighboring stations are $80 \mathrm{~km}$ apart for profile AA', $100 \mathrm{~km}$ for profile BB' and DD' and $20 \mathrm{~km}$ for profile CC', the shape of the spectra are similar along each profile. Also, along each profile, the peaks associated with the ice thickness are clear and the locations of the peaks shift towards lower or higher frequencies cohering to the variation of the corresponding ice thickness. There are four stations (N060, ST04, ST06, ST07) along the four profiles without peak frequencies related to their corresponding ice thicknesses. This may be caused by the bad coupling of the seismometer with the ice surface or possibly a complicated subglacial environment, for example, clear evidence indicates the existence of a sedimentary layer beneath station N060.

Having identified resonance frequencies of the ice sheet, we calculated the ice thickness using Eq. (1) with the average shear-wave velocity $-1900 \mathrm{~m} \mathrm{~s}^{-1}$. The Eq. (1) estimates, together with their relative errors to the correspond- 
ing Bedmap2 ice thickness are listed in Table 1 (hereafter the ice thickness estimations derived from the approximation Eq. (1) and $\mathrm{H} / \mathrm{V}$ spectrum inversions using model $\mathrm{A}$ and model B are defined as Eq. (1), DFA + Model A and DFA + Model B estimates, respectively). We projected the Eq. (1) estimates and the reference Bedmap2 ice thickness for stations along the four profiles in the upper elevation panels in Fig. 4. It is clear that the Eq. (1) estimates for some stations along the four profiles are close to the reference ice thickness like the E012, P071, and ST01 stations, while there are large deviations at some stations such as E018, N148, and ST02. It should be noted that the ice thickness obtained from the $\mathrm{H} / \mathrm{V}$ method reflects the average ice sheet thickness beneath each station in the scale of seismic wavelength (i.e., for a peak at a frequency of $0.2-1 \mathrm{~Hz}$ and seismic wavelength of $\sim 2.0 \mathrm{~km}$, the spatial resolution (or footprint) is about 2$10 \mathrm{~km})$.

The optimum shear-wave velocity models derived from $\mathrm{H} / \mathrm{V}$ spectrum inversion are presented in Fig. 5 and Supplement Fig. S3. The observed H / V spectrum together with the synthetic $\mathrm{H} / \mathrm{V}$ spectra using the two optimum shear-wave velocity models are plotted in Fig. 6 and shown in Supplement Fig. S4. As Fig. 6 and the Supplement Fig. S4 show, the synthetic $\mathrm{H} / \mathrm{V}$ spectra of the optimum inversion results for model A and model B at almost all stations, both fit the observed $\mathrm{H} / \mathrm{V}$ spectra in peak frequency and spectrum shape. However, the DFA + Model A estimates deviate substantially from the Bedmap2 thickness at most stations (such as N108, N148, GM02 and ST02 in Fig. 5), and the difference extends $1 \mathrm{~km}$ for some stations (Fig. 7). By contrast, the DFA + Model B estimates are consistent with the Bedmap2 thickness as the differences between them are mostly within $200 \mathrm{~m}$. The overall DFA + Model B estimates are listed in Table 1, as well as the relative errors to the corresponding Bedmap2 ice thickness. We also projected the DFA + Model $\mathrm{B}$ estimates for stations along the four profiles in the elevation panels seen in Fig. 4. This figure depicts a good consistency between the DFA + Model B estimates and the reference ice thickness as the ice thickness at 27 stations and 46 stations out of the 48 stations along the profiles are within 10 and $15 \%$ threshold of the Bedmap2 ice thickness.

The results of four different length seismic ambient noise records $(1,2,4,8 \mathrm{~h})$ used to obtain $\mathrm{H} / \mathrm{V}$ spectrum are displayed in Fig. 8 (and in Supplement Fig. S5). These plots show that the shape of the spectra of the four tested record lengths are similar to the shape determined using a record five days long. The peak frequencies of the four different length records are all within the margin of error for the peak frequency as determined with the five day long record. We also found that the longer the ambient noise record, the more stable the peak frequency, as there are slight shifts in the peak frequency when determined with $1 \mathrm{~h}$ records. This feature is obvious for stations with thin ice (less than $2 \mathrm{~km}$ ) such as stations E018 (Fig. 8), E014, E020, E024 and E028 (shown in Supplement Fig. S5). The quality of the H / V spectrum ob- tained from the one hour-long record for stations with thick ice (over $2 \mathrm{~km}$ ), however, is generally consistent with that determined with the five day long record. This consistency can also be seen for all stations when the length of noise record exceeds two hours.

\section{Discussion}

Bedmap2 ice thickness was used as reference to verify the Eq. (1), DFA + Model A and DFA + Model B estimates since we lacked actual ice thickness, as obtained from more direct and accurate ice-core drilling, RES and active seismic methods at or near each study site. Because of the various factors contributing to uncertainty in the Bedmap2 database such as data coverage, basal roughness, and ice thickness measurement and gridding error, the Bedmap2 ice thickness is not exactly accurate with uncertainty varying from site to site. We obtained the uncertainty of the Bedmap2 ice thickness at each station from the grids of ice thickness uncertainty (Fretwell et al., 2013, also, the uncertainty at our study sites can be roughly seen in Supplement Fig. S6). A close examination of the uncertainty of the Bedmap2 ice thickness reveals that the uncertainty at 52 stations ranges from $59 \mathrm{~m}$ to about $200 \mathrm{~m}$, and the uncertainty at 57 stations is below $300 \mathrm{~m}$. As the accuracy of the $\mathrm{H} / \mathrm{V}$ method is at the same scale as the uncertainty of the Bedmap2 ice thickness at the 57 stations, the Bedmap2 ice thicknesses are adequate to verify the results derived from the $\mathrm{H} / \mathrm{V}$ method. The remaining three stations including ST09, ST13 and ST14 are excluded for validation as the uncertainty of the reference ice thickness at these stations reaches $1000 \mathrm{~m}$.

A comparison of the DFA + Model B estimates and Bedmap2 database reveals that the differences in ice thickness at all the 57 stations are less than $400 \mathrm{~m}$; there are 34 stations whose differences are within $200 \mathrm{~m}$ and 48 stations within $300 \mathrm{~m}$; the maximum difference was $360 \mathrm{~m}$ at stations GM06 and N215. The relative errors of the DFA + Model B estimates to the corresponding Bedmap2 thickness of 23 stations, 36 stations, and 58 stations are within a 5, 10, and $15 \%$ threshold, respectively. Given that the Bedmap2 ice thickness are associated with certain uncertainties at each station (i.e., the relative errors of the uncertainty to the Bedmap2 ice thickness are within $10 \%$ at 49 stations) (Fretwell et al., 2013). In this sense, we conclude that the DFA + Model B estimates have comparable accuracy to the Bedmap2 ice thickness at the study sites.

Based on the homogenous ice sheet layer assumption, most of the Eq. (1) estimates are not compatible with Bedmap2 ice thickness (Figs. 4 and 7), as the differences at 25 stations can extend $400 \mathrm{~m}$ and at 10 stations are over $600 \mathrm{~m}$; the maximum difference reaches $910 \mathrm{~m}$ at station N036. Moreover, most of the DFA + Model A estimates based on the homogenous ice structure of model A also deviate largely from the reference Bedmap2 thickness (Fig. 7 

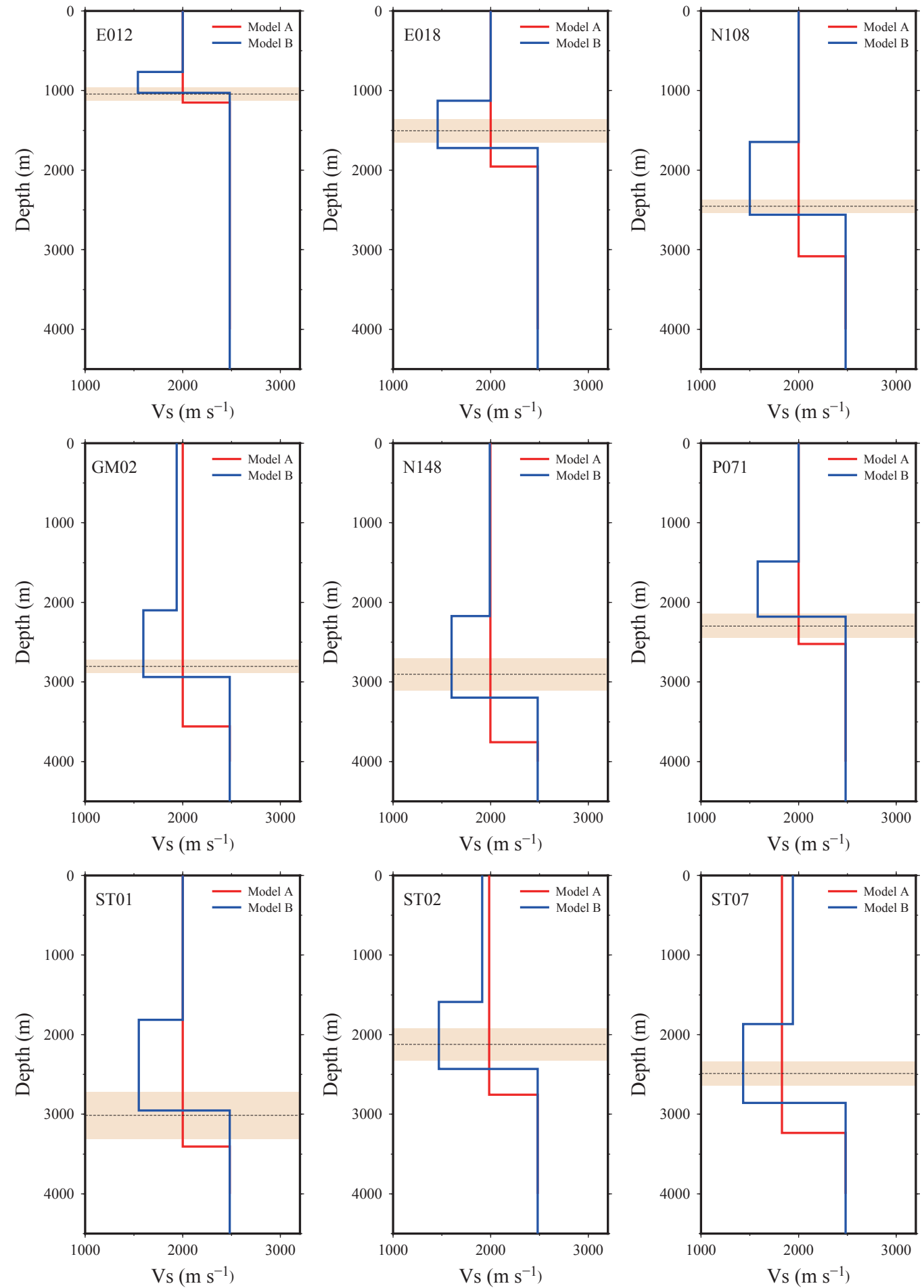

Figure 5. The optimum inversion shear-wave velocity models for the nine stations. The horizontal dashed line in each plot indicates the reference Bedmap2 ice thickness, and the shaded area shows the uncertainty of the Bedmap2 ice thickness. As can be seen, the inversion ice thickness results derived from the two-layer structure (model B) are much closer to the Bedmap2 thickness than those determined using the single ice layer (model A). 
Table 1. Ice thickness results obtained from this study (The resonance frequencies $f_{0}$ and the corresponding standard deviations $\sigma$ are listed in column 3. The Eq. (1) estimates and the associated errors $\Delta h$ are listed in column 4 . The relative errors of the Eq. (1) and DFA + Model B estimates to the Bedmap2 ice thickness are listed in column 5 and 7.)

\begin{tabular}{|c|c|c|c|c|c|c|}
\hline Station & Bedmap2 (km) & Resonance freq. $(\mathrm{Hz})$ & Eq. $(1)(\mathrm{km})^{\mathrm{a}}$ & Relative error $^{\mathrm{b}}$ & DFA + Model B $(\mathrm{km})$ & Relative error ${ }^{c}$ \\
\hline BENN & 1.56 & $0.222 \pm 0.034$ & $2.14 \pm 0.33$ & $37.18 \%$ & 1.73 & $10.90 \%$ \\
\hline BYRD & 2.16 & $0.222 \pm 0.022$ & $2.14 \pm 0.21$ & $0.93 \%$ & 2.33 & $7.87 \%$ \\
\hline E012 & 1.05 & $0.418 \pm 0.052$ & $1.14 \pm 0.14$ & $8.57 \%$ & 1.03 & $1.90 \%$ \\
\hline E014 & 0.66 & $0.914 \pm 0.085$ & $0.52 \pm 0.05$ & $21.21 \%$ & 0.60 & $9.09 \%$ \\
\hline E018 & 1.50 & $0.222 \pm 0.028$ & $2.14 \pm 0.27$ & $42.67 \%$ & 1.72 & $14.67 \%$ \\
\hline E020 & 1.75 & $0.200 \pm 0.011$ & $2.38 \pm 0.13$ & $36.00 \%$ & 2.01 & $14.86 \%$ \\
\hline E024 & 1.83 & $0.200 \pm 0.019$ & $2.38 \pm 0.22$ & $30.05 \%$ & 2.09 & $14.21 \%$ \\
\hline E026 & 1.40 & $0.215 \pm 0.028$ & $2.2 \pm 0.29$ & $57.14 \%$ & 1.61 & $15.00 \%$ \\
\hline E028 & 1.61 & $0.188 \pm 0.032$ & $2.5 \pm 0.44$ & $55.28 \%$ & 1.85 & $14.91 \%$ \\
\hline E030 & 2.02 & $0.177 \pm 0.024$ & $2.68 \pm 0.37$ & $32.67 \%$ & 2.32 & $14.85 \%$ \\
\hline GM01 & 3.10 & $0.155 \pm 0.018$ & $3.07 \pm 0.36$ & $0.97 \%$ & 3.12 & $0.65 \%$ \\
\hline GM02 & 2.81 & $0.159 \pm 0.014$ & $2.98 \pm 0.26$ & $6.05 \%$ & 2.94 & $4.63 \%$ \\
\hline GM03 & 2.52 & $0.159 \pm 0.018$ & $2.98 \pm 0.33$ & $18.25 \%$ & 2.88 & $14.29 \%$ \\
\hline GM04 & 2.80 & $0.157 \pm 0.015$ & $3.02 \pm 0.29$ & $7.86 \%$ & 3.08 & $10.00 \%$ \\
\hline GM05 & 3.47 & $0.146 \pm 0.020$ & $3.26 \pm 0.45$ & $6.05 \%$ & 3.17 & $8.65 \%$ \\
\hline GM06 & 3.47 & $0.150 \pm 0.015$ & $3.16 \pm 0.32$ & $8.93 \%$ & 3.10 & $10.66 \%$ \\
\hline GM07 & 3.03 & $0.148 \pm 0.012$ & $3.21 \pm 0.26$ & $5.94 \%$ & 3.08 & $1.65 \%$ \\
\hline JNCT & 1.19 & $0.349 \pm 0.031$ & $1.36 \pm 0.12$ & $14.29 \%$ & 1.26 & $5.88 \%$ \\
\hline N020 & 1.71 & $0.222 \pm 0.021$ & $2.14 \pm 0.21$ & $25.15 \%$ & 1.95 & $14.04 \%$ \\
\hline N028 & 2.06 & $0.197 \pm 0.020$ & $2.41 \pm 0.25$ & $16.99 \%$ & 2.24 & $8.74 \%$ \\
\hline N036 & 2.21 & $0.152 \pm 0.020$ & $3.12 \pm 0.41$ & $41.18 \%$ & 2.53 & $14.48 \%$ \\
\hline N044 & 2.21 & $0.169 \pm 0.023$ & $2.81 \pm 0.39$ & $27.15 \%$ & 2.51 & $13.57 \%$ \\
\hline N052 & 2.39 & $0.152 \pm 0.022$ & $3.12 \pm 0.45$ & $30.54 \%$ & 2.75 & $15.06 \%$ \\
\hline N068 & 2.87 & $0.155 \pm 0.014$ & $3.07 \pm 0.28$ & $6.97 \%$ & 2.98 & $3.83 \%$ \\
\hline N076 & 2.46 & $0.172 \pm 0.014$ & $2.76 \pm 0.23$ & $12.20 \%$ & 2.59 & $5.28 \%$ \\
\hline N084 & 2.47 & $0.183 \pm 0.016$ & $2.60 \pm 0.23$ & $5.26 \%$ & 2.59 & $4.86 \%$ \\
\hline N092 & 2.63 & $0.175 \pm 0.016$ & $2.72 \pm 0.25$ & $3.42 \%$ & 2.48 & $5.70 \%$ \\
\hline N100 & 2.68 & $0.167 \pm 0.015$ & $2.85 \pm 0.26$ & $6.34 \%$ & 2.68 & $0.00 \%$ \\
\hline N108 & 2.45 & $0.177 \pm 0.014$ & $2.68 \pm 0.21$ & $9.39 \%$ & 2.56 & $4.49 \%$ \\
\hline N116 & 2.50 & $0.175 \pm 0.024$ & $2.72 \pm 0.39$ & $8.80 \%$ & 2.46 & $1.60 \%$ \\
\hline N124 & 2.42 & $0.185 \pm 0.019$ & $2.56 \pm 0.26$ & $5.79 \%$ & 2.57 & $6.20 \%$ \\
\hline N132 & 3.24 & $0.146 \pm 0.018$ & $3.26 \pm 0.40$ & $0.62 \%$ & 3.07 & $5.25 \%$ \\
\hline N140 & 2.79 & $0.162 \pm 0.022$ & $2.93 \pm 0.42$ & $5.02 \%$ & 2.69 & $3.58 \%$ \\
\hline N148 & 2.9 & $0.137 \pm 0.017$ & $3.46 \pm 0.44$ & $19.31 \%$ & 3.20 & $10.34 \%$ \\
\hline N156 & 2.55 & $0.194 \pm 0.016$ & $2.45 \pm 0.20$ & $3.92 \%$ & 2.48 & $2.75 \%$ \\
\hline N165 & 2.81 & $0.150 \pm 0.021$ & $3.16 \pm 0.44$ & $12.46 \%$ & 2.95 & $4.98 \%$ \\
\hline N173 & 2.38 & $0.185 \pm 0.017$ & $2.56 \pm 0.24$ & $7.56 \%$ & 2.54 & $6.72 \%$ \\
\hline N182 & 2.42 & $0.191 \pm 0.014$ & $2.49 \pm 0.19$ & $2.89 \%$ & 2.54 & $4.96 \%$ \\
\hline N190 & 3.01 & $0.144 \pm 0.017$ & $3.31 \pm 0.41$ & $9.97 \%$ & 3.15 & $4.65 \%$ \\
\hline N198 & 3.32 & $0.148 \pm 0.017$ & $3.21 \pm 0.38$ & $3.31 \%$ & 3.30 & $0.60 \%$ \\
\hline N206 & 2.96 & $0.159 \pm 0.022$ & $2.98 \pm 0.41$ & $0.68 \%$ & 2.61 & $11.82 \%$ \\
\hline $\mathrm{N} 215$ & 3.48 & $0.155 \pm 0.017$ & $3.07 \pm 0.33$ & $11.78 \%$ & 3.12 & $10.34 \%$ \\
\hline P061 & 3.16 & $0.135 \pm 0.018$ & $3.52 \pm 0.46$ & $11.39 \%$ & 3.17 & $0.63 \%$ \\
\hline P071 & 2.3 & $0.194 \pm 0.018$ & $2.45 \pm 0.23$ & $6.52 \%$ & 2.18 & $5.22 \%$ \\
\hline P080 & 2.47 & $0.188 \pm 0.018$ & $2.52 \pm 0.25$ & $2.02 \%$ & 2.52 & $2.02 \%$ \\
\hline P090 & 2.34 & $0.212 \pm 0.022$ & $2.24 \pm 0.23$ & $4.27 \%$ & 2.09 & $10.68 \%$ \\
\hline P116 & 2 & $0.222 \pm 0.023$ & $2.14 \pm 0.22$ & $7.00 \%$ & 1.93 & $3.50 \%$ \\
\hline P124 & 1.54 & $0.314 \pm 0.033$ & $1.51 \pm 0.16$ & $1.95 \%$ & 1.47 & $4.55 \%$ \\
\hline ST01 & 3.02 & $0.157 \pm 0.015$ & $3.02 \pm 0.28$ & $0.00 \%$ & 2.95 & $2.32 \%$ \\
\hline ST02 & 2.12 & $0.164 \pm 0.018$ & $2.89 \pm 0.32$ & $36.32 \%$ & 2.43 & $14.62 \%$ \\
\hline
\end{tabular}


Table 1. Continued.

\begin{tabular}{|c|c|c|c|c|c|c|}
\hline Station & Bedmap2 (km) & Resonance freq. (Hz) & Equation (1) (km) & Relative error & DFA + Model B $(\mathrm{km})$ & Relative error \\
\hline ST03 & 1.93 & $0.236 \pm 0.019$ & $2.01 \pm 0.16$ & $4.35 \%$ & 1.96 & $1.33 \%$ \\
\hline ST08 & 2.18 & $0.152 \pm 0.016$ & $3.12 \pm 0.34$ & $43.12 \%$ & 2.50 & $14.68 \%$ \\
\hline ST09 & 2.32 & $0.157 \pm 0.020$ & $3.02 \pm 0.4$ & $30.17 \%$ & 2.66 & $14.66 \%$ \\
\hline ST10 & 1.23 & $0.266 \pm 0.030$ & $1.79 \pm 0.21$ & $45.53 \%$ & 1.51 & $22.76 \%$ \\
\hline ST12 & 1.89 & $0.185 \pm 0.020$ & $2.56 \pm 0.28$ & $35.45 \%$ & 2.15 & $13.76 \%$ \\
\hline ST13 & 1.94 & $0.167 \pm 0.018$ & $2.85 \pm 0.32$ & $46.91 \%$ & 2.23 & $14.95 \%$ \\
\hline ST14 & 1.54 & $0.339 \pm 0.038$ & $1.40 \pm 0.16$ & $9.09 \%$ & 1.44 & $6.49 \%$ \\
\hline SWEI & 2.84 & $0.162 \pm 0.017$ & $2.93 \pm 0.31$ & $3.17 \%$ & 2.93 & $3.17 \%$ \\
\hline TIMW & 2.57 & $0.175 \pm 0.020$ & $2.72 \pm 0.32$ & $5.84 \%$ & 2.65 & $3.11 \%$ \\
\hline WAIS & 3.37 & $0.127 \pm 0.015$ & $3.73 \pm 0.43$ & $10.68 \%$ & 3.71 & $10.09 \%$ \\
\hline
\end{tabular}

${ }^{a} \Delta h=\left(\left(\frac{V_{\mathrm{s}}}{f_{0}}-\frac{V_{\mathrm{s}}}{f_{0}+\sigma}\right)+\left(\frac{V_{\mathrm{s}}}{f_{0}-\sigma}-\frac{V_{\mathrm{s}}}{f_{0}}\right)\right) / 2, \frac{\mathrm{b}}{\frac{\mid \text { Equation(1)-Bedmap } 2 \mid}{\text { Bedmap2 }}} \cdot 100 \%, \mathrm{c} \frac{\mid \mathrm{DFA}+\text { ModelB-Bedmap2 } \mid}{\text { Bedmap2 }} \cdot 100 \%$
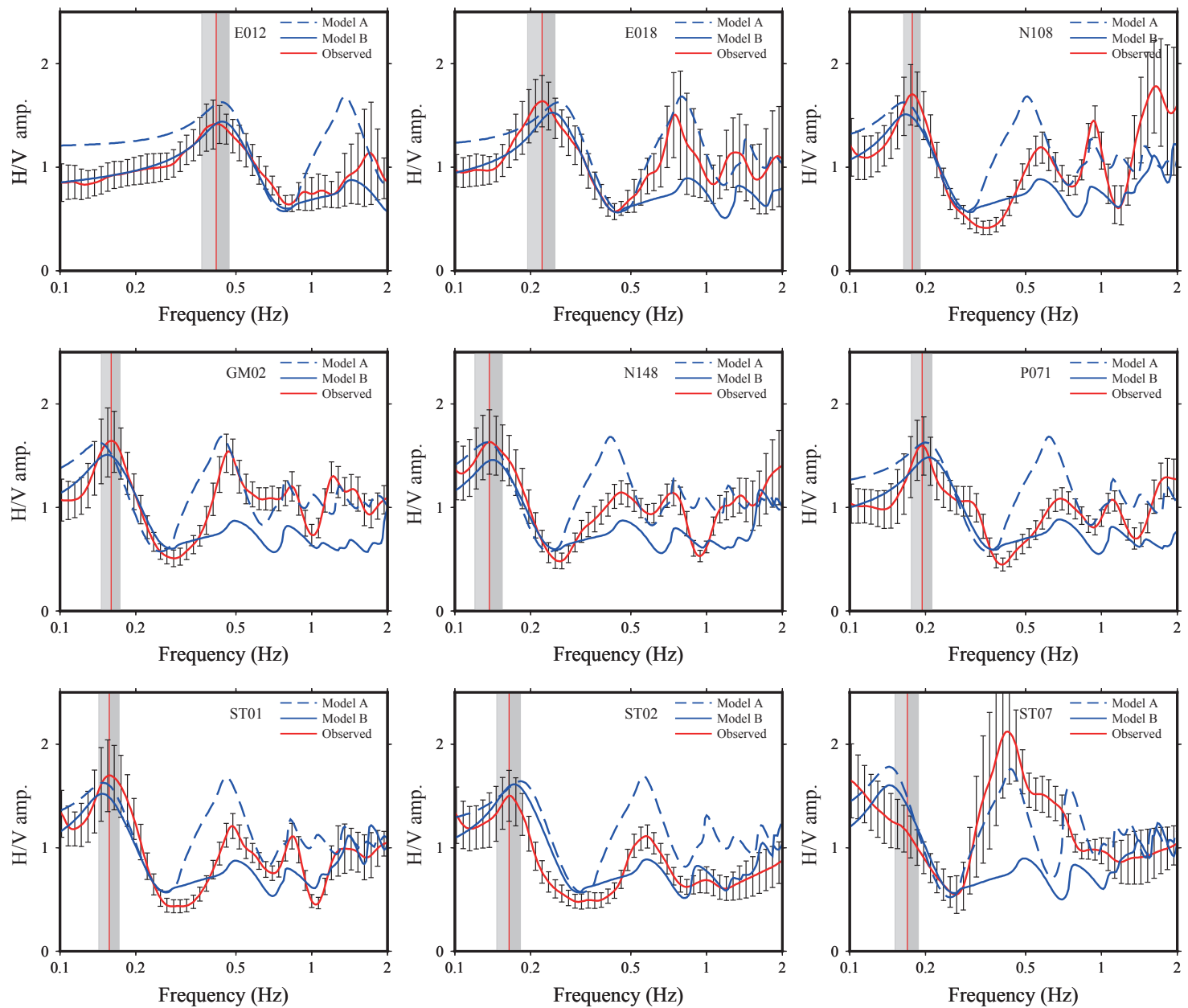

Figure 6. The synthetic H / V spectra and the observed H / V spectrum for the nine stations. The synthetic H / V spectra are modeled using the optimum inversion shear-wave velocity profiles for model A and model B. In all plots except for the last one, the vertical bars are the same as those in Fig. 3 (i.e., the real peak frequency and the associated standard deviation). As for the last one, the peak frequency is approximately calculated using Eq. (1) with its Bedmap2 ice thickness, and the deviation is also approximated with a relative error of $10 \%$ to its peak frequency. The two synthetic $\mathrm{H} / \mathrm{V}$ spectra are both in good agreement with the observed $\mathrm{H} / \mathrm{V}$ spectrum. Note that the amplitudes of the synthetic $\mathrm{H} / \mathrm{V}$ spectra are normalized by dividing the whole frequency band by two. 

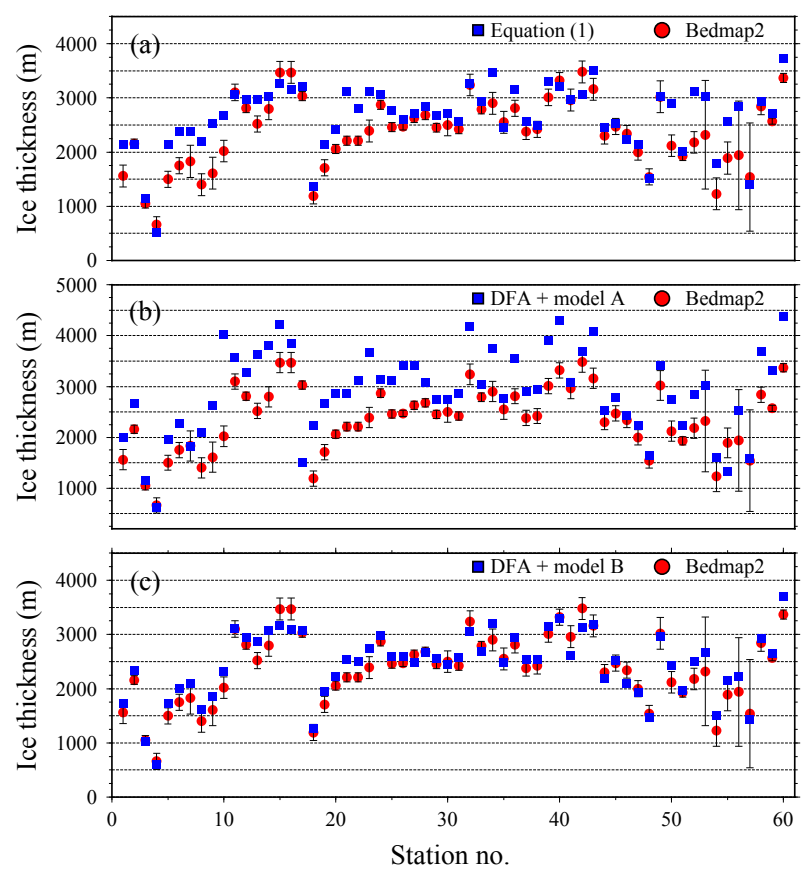

Figure 7. Ice thickness derived from the $\mathrm{H} / \mathrm{V}$ method versus the reference Bedmap2 ice thickness. The station number of this figure is in the same order as the stations listed in Table 1. The blue squares in panel (a), (b) and (c) represent Eq. (1), DFA + Model A and DFA + Model B estimates, respectively. The red circles in each panel denote the Bedmap2 ice thickness and each Bedmap2 value is marked with its corresponding error bar obtained from the uncertainty grids (Fretwell et al., 2013).

and Supplement Fig. S3). These large deviations cannot be attributed to the uncertainty in the reference Bedmap2 ice thickness since they made minor contributions to the large differences.

The DFA + Model B estimates, however, are in good concurrence with the Bedmap2 database (Table 1). A close examination of the DFA + Model B estimates shows that it refined the Eq. (1) estimates at 47 stations to varying degrees. For example, at stations E012 and N036 Eq. (1) estimates deviate from Bedmap2 at 90 and $910 \mathrm{~m}$, while the DFA + Model B estimates refine the gaps to 20 and $320 \mathrm{~m}$.

We compared our results with those found in Wittlinger and Farra (2012). Using the PRF method and a grid search stacking technique, they found that the Antarctic ice is stratified, possibly due to the preferred orientation of ice crystals and fine layering of soft and hard ice layers under pressure. In Fig. 9, we present the ice sheet structure for 12 stations common to both studies. It is clear that the interface separating the upper and the lower ice sheet layers, determined using the $\mathrm{H} / \mathrm{V}$ method and the PRF method, is consistent for almost all stations.

The agreement of two-layer ice sheet thickness with the Bedmap2 database, and the consistency of our results to Wit- tlinger and Farra's (2012) results, as well as the large deviation of Eq. (1) estimates and DFA + Model A estimates, jointly support the thesis that the two-layered ice sheet models are more reasonable than an homogeneous ice sheet layer assumption. Moreover, the Eq. (1) estimates of 28 stations were close to the reference Bedmap2 database. This consistency, however, does not strongly support the homogenous ice sheet layer assumption, as it can be attributed to the fact that the $V_{\mathrm{s}}$ values adopted in approximate estimation were coincidental with the average velocity of the two-layer $V_{\mathrm{s}}$ models.

The examples presented in this work clearly show that the $\mathrm{H} / \mathrm{V}$ method with seismic ambient noise can be effectively used to measure ice sheet thickness. However, there are also some limitations that may affect the results. Shear-wave velocity $\left(V_{\mathrm{s}}\right)$, as the key parameter for $\mathrm{H} / \mathrm{V}$ spectrum inversion and approximate estimation using Eq. (1), will significantly affect the effectiveness and uncertainty of the $\mathrm{H} / \mathrm{V}$ method. We can see from Fig. 6 that the synthetic H / V spectra from the optimum $V_{\mathrm{s}}$ profiles of model $\mathrm{A}$ and model B for the N108, GM02 and N148 stations, match the observed H / V spectrum. The DFA + Model A estimates and the DFA + Model B estimates at these stations, however, are remarkably different as the DFA + Model B estimates more closely match the reference Bedmap2 ice thickness than the DFA + Model A estimates (Fig. 5). Also evident in these results is a directly proportional relationship between ice thickness and the $V_{\mathrm{s}}$ as expected from Eq. (1) in approximate estimation. Given a $\sim 5 \%$ variation in the average shear-wave speed of the ice layer, then ice sheet thickness estimation will result in a similar variation such as $150 \mathrm{~m}$ for a station with $3 \mathrm{~km}$ thickness. Accurate known $V_{\mathrm{s}}$ profiles are therefore prerequisites when obtaining reliable $\mathrm{H} / \mathrm{V}$ spectrum inversion results, as well as for approximate estimations using Eq. (1).

It is evident that the longer the noise record the more stable the observed peak frequency, as the sources of the seismic ambient noise are more evenly distributed, both spatially and temporally. This is significant for stations with thin ice primarily due to the fact that thin ice sheet layers are excited by high-frequency waves such as wind and other sources (Picotti et al., 2017). Thus, a longer ambient noise record can improve the stability of the $\mathrm{H} / \mathrm{V}$ spectrum. In our study, we found that the quality of the $\mathrm{H} / \mathrm{V}$ spectrum is generally better for thick ice sheet layers than for thin ice sheet such as stations E012, E018, E024, E026 and E028, which have relatively smaller ice thicknesses than other stations. The H / V spectra for these stations exhibited less stability when the lengths of noise records decreased (Fig. 8 and Supplement Fig. S5). Their peak frequencies obtained from a one hour long record deviate slightly from the peak frequency determined with a five day record. These deviations could consequently lead to uncertainties in ice thickness estimation. For stations with thick ice in comparison, both the shape and the peak frequency determined using a one hour long record are generally consistent with those obtained from a five day long 

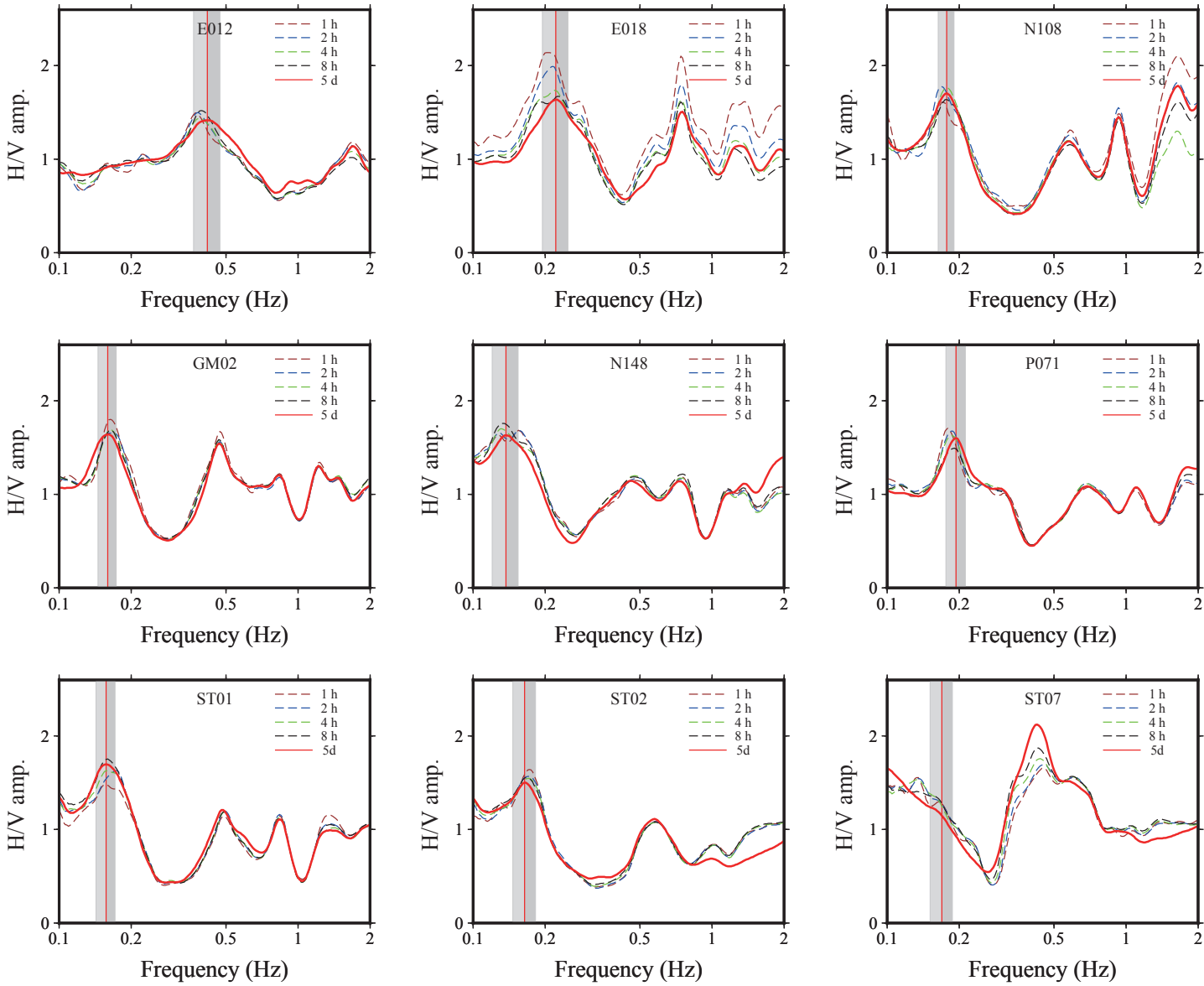

Figure 8. H / V spectra calculated using different lengths of ambient noise records. The vertical bars in all panels except for the last one represent the peak frequencies and the corresponding standard deviations the same as those in Fig. 3 and Fig. 6. There is a good consistency between $\mathrm{H} / \mathrm{V}$ spectra determined with different testing length of noise records $(1,2,4$ and $8 \mathrm{~h})$ and the spectrum from the five day long record, both in locations of peak frequencies and the spectra shape. However, the peak frequency obtained from the $1 \mathrm{~h}$ record deviates slightly the peak frequency determined using 5 day long record for the E012 station.

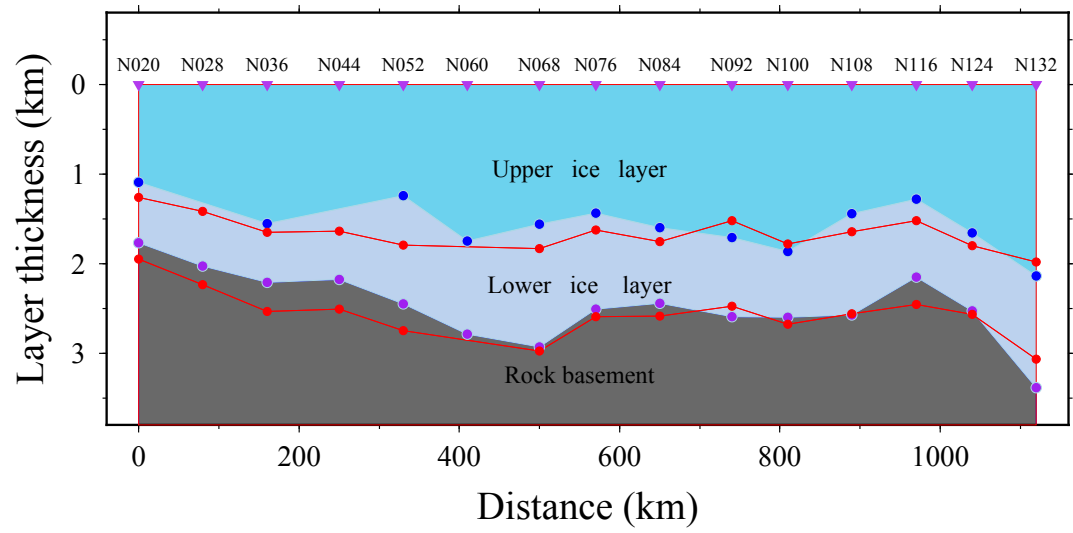

Figure 9. Comparisons of the two-layer ice sheet structure obtained from our study and Wittlinger and Farra's (2012). The red dots shown at a shallower depth denote the interface between the upper and the lower ice sheet obtained in this study. The interface is generally consistent with that determined with the PRF method and a grid search stacking technique (as shown the blue dots) (Wittlinger and Farra, 2012, Table 1). The red dots shown at a deeper depth represent the overall ice thickness derived from model B, which is also consistent with the radar ice thickness (as the purple dots show) adopted by Wittlinger and Farra (2012). 
record. Given that the variation of ice thickness at the study sites $(600 \mathrm{~m}$ to about $4 \mathrm{~km})$, generally covers the range of the whole Antarctic ice sheet thickness, we would suggest a uniform record length of two hours in $\mathrm{H} / \mathrm{V}$ method application in Antarctica, in terms of both stability and efficiency.

\section{Conclusions}

The $\mathrm{H} / \mathrm{V}$ method is proposed as a reliable, efficient method for investigating the Antarctic ice sheet thickness. The H / V method is effective for identifying the fundamental resonance frequency correlated to the ice sheet thickness. In this approach, the ambient noise recording length can be as short as $2 \mathrm{~h}$, reducing costs and increasing efficiency. Equation (1) can retrieve a fast estimation of the ice thickness but, should be used with care since the shear-wave velocity varies at different sites. H / V spectrum inversion, however, unlike estimation with Eq. (1), is robust and can obtain reliable ice thickness results with given seismic properties. Moreover, the $\mathrm{H} / \mathrm{V}$ spectrum inversion ice sheet thickness results are consistent with the reference Bedmap2 database. Our results also support the argument that the Antarctic ice sheet has a two-layer structure. The $\mathrm{H} / \mathrm{V}$ method is an excellent approach that provides new and independent ice sheet thickness estimations. What makes this new approach most attractive, is the ease and economy of seismic ambient noise waveform collection when deploying a single seismometer for short time intervals. Finally, we hope that specific seismic experiments can obtain more accurate shear-wave velocity profiles in the ice sheet, thus making better constraints for $\mathrm{H} / \mathrm{V}$ method results.

Data availability. The IRIS Data Management Center was used for access to waveforms used in this study. The seismic data can be downloaded from the IRIS facility by BREQ_FAST requests.

\section{The Supplement related to this article is available online at https://doi.org/10.5194/tc-12-795-2018-supplement.}

Competing interests. The authors declare that they have no conflict of interest.

Acknowledgements. We thank the editor, Kenny Matsuoka, and two reviewers, Andreas Köhler and Adam Booth for their critical and helpful comments and suggestions that greatly improved the manuscript. We thank Sidao Ni for helpful discussion on the manuscript. This work was supported by the State Key Program of National Natural Science of China under grant no. 41531069, the Chinese Polar Environment Comprehensive Investigation and Assessment Programs under grant no. CHINARE2017-02-03 and the Special Funds for Basic Scientific Research of Universities under grant no. 2015644020201. Seismic data are obtained from the Incorporated Research Institutions for Seismology (IRIS). Figures in this study were plotted using Generic Mapping Tools (GMT).

Edited by: Kenny Matsuoka

Reviewed by: Adam Booth and Andreas Köhler

\section{References}

Anthony, R. E., Aster, R. C., Wiens, D., Nyblade, A., Anandakrishnan, S., Huerta, A., Winberry, J. P., Wilson, T., and Rowe, C.: The seismic noise environment of Antarctica, Seismol. Res. Lett., 86, 89-100, 2015.

Arai, H. and Tokimatsu, K.: S-wave velocity profiling by inversion of microtremor H / V spectrum, B. Seismol. Soc. Am., 94, 5363, 2004

Aster, R. C. and Winberry, J. P.: Glacial Seismology, Rep. Prog. Phys., 80, 1-67, 2017.

Bamber, J. L., Layberry, R. L., and Gogineni, S. P.: A new ice thickness and bed data set for the Greenland ice sheet: 1 . Measurement, data reduction, and errors, J. Geophys. Res.-Atmos., 106 , 33773-33780, 2001.

Bard, P. Y.: Microtremor measurements: a tool for site effect estimation, in: Proceedings of the 2nd international symposium on the effects of surface geology on seismic motion, Yokohama, 12511279, 1998.

Bard, P. Y. and Site Effects aSsessment using AMbient Excitations Team: Report D23.12, Guidelines for the implementation of the $\mathrm{H} / \mathrm{V}$ spectral ratio technique on ambient vibrations measurements, processing and interpretation, in European Commission: Research general directorate, Project No. EVG1-CT-200000026, SESAME, 62 pp., 2005.

Bentley, C. and Ostenso, N.: Glacial and Subglacial Topography of West Antarctica, J. Glaciol., 3, 882-911, 1961.

Bentley, C. R.: The structure of Antarctica and its ice cover, in: Research in Geophysics Vol. 2, Solid Earth and Interface Phenomena, edited by: Odishaw, H., MIT Press, Cambridge, Mass., 335-389, 1964.

Bonnefoy-Claudet, S., Cornou, C., Bard, P. Y., Cotton, F., Moczo, P., Kristek, J., and Fäh, D.: H / V ratio: a tool for site effects evaluation. Results from 1-D noise simulations, Geophys. J. Int., 167, 827-837, 2006.

Budd, W. F.: Antarctica and global change, Climatic Change, 18, 271-299, 1991.

Chaput, J., Aster, R. C., Huerta, A., Sun, X., Lloyd, A., Wiens, D., Nyblade, A., Anandakrishnan, S., Winberry, J. P., and Wilson, T.: The crustal thickness of West Antarctica, J. Geophys. Res.-Sol. Ea., 119, 378-395, 2014.

Civico, R., Sapia, V., Di Giulio, G., Villani, F., Pucci, S., Baccheschi, P., and Smedile, A.: Geometry and evolution of a faultcontrolled Quaternary basin by means of TDEM and singlestation ambient vibration surveys: the example of the 2009 L'Aquila earthquake area, J. Geophys. Res.-Sol. Ea., 122, 22362259, 2017.

Cui, X. B., Sun, B., Su, X. G., and Guo, J. X.: Distribution of ice thickness and subglacial topography of the "Chinese Wall" 
around Kunlun Station, East Antarctica, Appl. Geophys., 13, 209-216, https://doi.org/10.1007/s11770-016-0539-z, 2016.

Drewry, D. J., Jordan, S. R., and Jankowski, E.: Measured properties of the Antarctic ice sheet: surface configuration, ice thickness, volume and bedrock characteristics, Ann. Glaciol., 3, 8391, 1982.

Evans, S. and Robin, G. Q.: Glacier depth sounding from the air, Nature, 210, 883-885, 1966.

Evans, S. and Smith, B. M. E.: A radio echo equipment for depth sounding in polar ice sheets, J. Phys. E Sci. Instrum., 2, 131-136, https://doi.org/10.1088/0022-3735/2/2/302, 1969.

Fäh, D., Kind, F., and Giardini, D.: A theoretical investigation of average H / V ratios, Geophys. J. Int., 145, 535-549, 2001.

Fäh, D., Kind, F., and Giardini, D.: Inversion of local S-wave velocity structures from average $\mathrm{H} / \mathrm{V}$ ratios and their use for the estimation of site-effects, J. Seismol., 7, 449-467, 2003.

Fretwell, P., Pritchard, H. D., Vaughan, D. G., Bamber, J. L., Barrand, N. E., Bell, R., Bianchi, C., Bingham, R. G., Blankenship, D. D., Casassa, G., Catania, G., Callens, D., Conway, H., Cook, A. J., Corr, H. F. J., Damaske, D., Damm, V., Ferraccioli, F., Forsberg, R., Fujita, S., Gim, Y., Gogineni, P., Griggs, J. A., Hindmarsh, R. C. A., Holmlund, P., Holt, J. W., Jacobel, R. W., Jenkins, A., Jokat, W., Jordan, T., King, E. C., Kohler, J., Krabill, W., Riger-Kusk, M., Langley, K. A., Leitchenkov, G., Leuschen, C., Luyendyk, B. P., Matsuoka, K., Mouginot, J., Nitsche, F. O., Nogi, Y., Nost, O. A., Popov, S. V., Rignot, E., Rippin, D. M., Rivera, A., Roberts, J., Ross, N., Siegert, M. J., Smith, A. M., Steinhage, D., Studinger, M., Sun, B., Tinto, B. K., Welch, B. C., Wilson, D., Young, D. A., Xiangbin, C., and Zirizzotti, A.: Bedmap2: improved ice bed, surface and thickness datasets for Antarctica, The Cryosphere, 7, 375-393, https://doi.org/10.5194/tc-7-375-2013, 2013.

García-Jerez, A., Luzón, F., Sánchez-Sesma, F. J., Lunedei, E., Albarello, D., Santoyo, M. A., and Almendros, J.: Diffuse elastic wavefield within a simple crustal model. Some consequences for low and high frequencies, J. Geophys. Res.-Sol. Ea., 118, 55775595, 2013.

García-Jerez, A., Piña-Flores, J., Sánchez-Sesma, F. J., Luzón, F., and Perton, M.: A computer code for forward calculation and inversion of the $\mathrm{H} / \mathrm{V}$ spectral ratio under the diffuse field assumption, Comput. Geosci., 97, 67-78, 2016.

Gogineni, S., Tammana, D., Braaten, D., Leuschen, C., Akins, T., Legarsky, J., Kanagaratnam, P., Stiles, J., Allen, C., and Jezek, K.: Coherent radar ice thickness measurements over the Greenland ice sheet, J. Geophys. Res.-Atmos., 106, 33761-33772, 2001.

Hanna, E., Navarro, F. J., Pattyn, F., Domingues, C. M., Fettweis, X., Ivins, E. R., Nicholls, R. J., Ritz, C., Smith, B., Tulaczyk, S., Whitehouse, P. L., and Zwally, H. J.: Ice-sheet mass balance and climate change, Nature, 498, 51-59, 2013.

Hansen, S. E., Julia, J., Nyblade, A. A., Pyle, M. L., Wiens, D. A., and Anandakrishnan, S.: Using $S$ wave receiver functions to estimate crustal structure beneath ice sheets: An application to the Transantarctic Mountains and East Antarctic craton, Geochem. Geophy. Geosy., 10, Q08014, https://doi.org/10.1029/2009GC002576, 2009.

Hansen, S. E., Nyblade, A. A., Heeszel, D. S., Wiens, D. A., Shore, P., and Kanao, M.: Crustal structure of the Gamburtsev Mountains, East Antarctica, from S-wave receiver functions and
Rayleigh wave phase velocities, Earth Planet. Sc. Lett., 300, 395401, 2010.

Herak, M.: ModelHVSR-A Matlab ${ }^{\circledR}$ tool to model horizontal-tovertical spectral ratio of ambient noise, Comput. Geosci., 34, 1514-1526, 2008. Ibs-von Seht, M. and Wohlenberg, J.: Microtremor measurements used to map thickness of soft sediments, B. Seismol. Soc. Am., 89, 250-259, 1999.

Kim, K. Y., Lee, J., Hong, M. H., Hong, J. K., Jin, Y. K., and Shon, H.: Seismic and radar investigations of Fourcade Glacier on King George Island, Antarctica, Polar Res., 29, 298-310, 2010.

Konno, K. and Ohmachi, T.: Ground-motion characteristics estimated from spectral ratio between horizontal and vertical components of microtremor, B. Seismol. Soc. Am., 88, 228-241, 1998.

Lachetl, C. and Bard, P. Y.: Numerical and theoretical investigations on the possibilities and limitations of Nakamura's technique, J. Phys. Earth, 42, 377-397, 1994.

Langston, C. A. and Horton, S. P.: Three-dimensional seismicvelocity model for the unconsolidated Mississippi embayment sediments from $\mathrm{H} / \mathrm{V}$ ambient noise measurements, B. Seismol. Soc. Am., 104, 2349-2358, 2014.

Lawrence, J. F., Wiens, D. A., Nyblade, A. A., Anandakrishnan, S., Shore, P. J., and Voigt, D.: Crust and upper mantle structure of the Transantarctic Mountains and surrounding regions from receiver functions, surface waves, and gravity: implications for uplift models, Geochem. Geophy. Geosy., 7, Q10011, https://doi.org/10.1029/2006GC001282, 2006.

Lévêque, J. J., Maggi, A., and Souriau, A.: Seismological constraints on ice properties at Dome C, Antarctica, from horizontal to vertical spectral ratios, Antarct. Sci., 22, 572-579, 2010.

Lunedei, E. and Albarello, D.: On the seismic noise wavefield in a weakly dissipative layered Earth, Geophys. J. Int., 177, 10011014, 2009.

Lunedei, E. and Albarello, D.: Theoretical HVSR curves from full wavefield modelling of ambient vibrations in a weakly dissipative layered Earth, Geophys. J. Int., 181, 1093-1108, 2010.

Lunedei, E. and Malischewsky, P.: A review and some new issues on the theory of the $\mathrm{H} / \mathrm{V}$ technique for ambient vibrations. Perspectives on European Earthquake Engineering and Seismology, Springer International Publishing, 371-394, 2015.

Lythe, M. B., Vaughan, D. G., and The BEDMAP Consortium: BEDMAP: A new ice thickness and subglacial topographic model of Antarctica, J. Geophys. Res.-Sol. Ea., 106, 1133511351, 2001.

Nakamura, Y.: A method for dynamic characteristics estimation of subsurface using microtremor on the ground surface, Railway Technical Research Institute, Quarterly Reports 30.1, 1989.

Nakamura, Y.: On the H / V spectrum, in: Proceedings of the 14th world conference on earthquake engineering (WCEE), Beijing, 2008.

Nogoshi, M. and Igarashi, T.: On the amplitude characteristics of microtremor (part 2), J. Seismol. Soc. Japan, 24, 26-40, 1971.

Parolai, S., Bormann, P., and Milkereit, C.: New relationships between Vs, thickness of sediments, and resonance frequency calculated by the $\mathrm{H} / \mathrm{V}$ ratio of seismic noise for the Cologne area (Germany), B. Seismol. Soc. Am., 92, 2521-2527, 2002.

Picotti, S., Francese, R., Giorgi, M., Pettenati, F., and Carcione, J. M.: Estimation of glacier thicknesses and basal properties using the horizontal-to-vertical component spectral ratio (HVSR) technique from passive seismic data, J. Glaciol., 63, 229-248, 2017. 
Podolskiy, E. A. and Walter, F.: Cryo-seismology, Rev. Geophys., 54, 708-758, https://doi.org/10.1002/2016RG000526, 2016.

Ramirez, C., Nyblade, A., Hansen, S. E., Wiens, D. A., Anandakrishnan, S., Aster, R. C., Huerta, A. D., and Wilson, T.: Crustal and upper-mantle structure beneath ice-covered regions in Antarctica from S-wave receiver functions and implications for heat flow, Geophys. J. Int., 204, 1636-1648, 2016.

Robin, G. Q.: Radio-echo sounding applied to the investigation of the ice thickness and sub-ice relief of Antarctica, in: Symposium on Antarctic Geology and Solid Earth Geophysics, Oslo, 6-15 August 1970, 675-682, 1972.

Sánchez-Sesma, F. J. and Campillo, M.: Retrieval of the Green's function from cross correlation: the canonical elastic problem, B. Seismol. Soc. Am., 96, 1182-1191, 2006.

Sánchez-Sesma, F. J., Rodríguez, M., Iturrarán-Viveros, U., Luzón, F., Campillo, M., Margerin, L., García-Jerez, A., Suarez, M., Santoyo, M. A., and Rodríguez-Castellanos, A.: A theory for microtremor H / V spectral ratio: Application for a layered medium, Geophys. J. Int., 186, 221-225, 2011.

Shapiro, N. M. and Campillo, M.: Emergence of broadband Rayleigh waves from correlations of the ambient seismic noise, Geophys. Res. Lett., 31, L07614, https://doi.org/10.1029/2004GL019491, 2004.
Tuan, T. T., Scherbaum, F., and Malischewsky, P. G.: On the relationship of peaks and troughs of the ellipticity $(\mathrm{H} / \mathrm{V})$ of Rayleigh waves and the transmission response of single layer over half-space models, Geophys. J. Int., 184, 793-800, 2011.

Wathelet, M., Jongmans, D., and Ohrnberger, M.: Surface wave inversion using a direct search algorithm and its application to ambient vibration measurements, Near Surf. Geophys., 2, 211-221, 2004.

Wittlinger, G. and Farra, V.: Observation of low shear wave velocity at the base of the polar ice sheets: evidence for enhanced anisotropy, Geophys. J. Int., 190, 391-405, 2012.

Wittlinger, G. and Farra, V.: Evidence of unfrozen liquids and seismic anisotropy at the base of the polar ice sheets, Polar Sci., 9, 66-79, 2015.

Yan, P., Li, Z. W., Li, F., Yang, Y. D., Hao, W. F., and Zhou, L.: Antarctic ice sheet thickness derived from teleseismic receiver functions, Chinese J. Geophys.-Ch., 60, 3780-3792, 2017.

Zhan, Z., Tsai, V. C., Jackson, J. M., and Helmberger, D.: Ambient noise correlation on the Amery Ice Shelf, east Antarctica, Geophys. J. Int., 196, 1796-802, 2014. 